\title{
Kant, the transcendental designation of I, and the direct reference theory
}

\author{
(Kant, la designación transcendental de Yo y la teoría de la referencia directa)
}

\author{
Luca Forgione* \\ University of Basilicata, Italia
}

\begin{abstract}
The aim of this paper is to address the semantic issue of the nature of the representation $I$ and of the transcendental designation, i.e., the self-referential apparatus involved in transcendental apperception. The $I$ think, the bare or empty representation $I$, is the representational vehicle of the concept of transcendental subject; as such, it is a simple representation. The awareness of oneself as thinking is only expressed by the $I$ : the intellectual representation which performs a referential function of the spontaneity of a thinking subject. To begin with, what exactly does Kant mean when he states that $I$ is a simple and empty representation? Secondly, can the features of the representation $I$ and the correlative transcendental designation explain the indexical nature of the $I$ ? Thirdly, do the Kantian considerations on indexicality anticipate any of the semantic elements or, if nothing else, the spirit of the direct reference theory?
\end{abstract}

KEYWORDS: Kant; I think; transcendental apperception; transcendental designation; indexicality; direct reference theory.

RESUMEN: El propósito de este artículo es la consideración del aspecto semántico de la naturaleza de la representación Yo y de la designación transcendental, i.e., el aparato auto-referencial implicado en la apercepción transcendental. El yo pienso, la mera representación vacía yo, es el vehiculo representacional del concepto de sujeto transcendental; como tal, es una representación simple. La consciencia de uno como pensante solo se expresa por el yo: la representación intelectual que realiza una función referencial de la espontaneidad de un sujeto pensante. Para empezar, ¿qué quiere decir Kant exactamente cuando afirma que yo es una representación simple y vacia? En segundo lugar, ¿pueden los aspectos de la representación yo y la designación transcendental correlativa explicar la naturaleza indéxica del yo? Tercero, anticipan las consideraciones kantianas sobre la indexicalidad alguno de los elementos o, al menos, el espiritu de la teoría directa de la referencia?

PALABRAS CLAVE: Kant; yo pienso; apercepción transcendental; designación transcendental; indexicalidad; teoria de la referencia directa.

* Correspondence to: Luca Forgione. Department of Humanities. University of Basilicata. Via Nazario Sauro 85. 85100 Potenza. Italia luca.forgione@unibas.it - http://orcid.org/0000-0002-4916-9515

How to cite: Forgione, Luca. (2019). "Kant, the transcendental designation of I, and the direct reference theory»; Theoria. An International Journal for Theory, History and Foundations of Science, 34(1), 31-49. (https://doi.org/10.1387/theoria.19324).

Received: 18 February, 2018; Final version: 28 April, 2018.

ISSN 0495-4548 - eISSN 2171-679X / (C) 2019 UPV/EHU 


\section{Preliminaries}

Three key issues emerge from the discussion of 'I think': 1) a semantic problem connected to the type of reference of the representation 'I', 2) an epistemic problem regarding the type of knowledge relative to the thinking subject produced by the representation 'I think', and 3) a strictly metaphysical problem associated with the features assigned to the thinking subject's nature.,

The aim of this paper is to address the semantic issue of the nature of $I$ and of the transcendental designation, i.e., the self-referential apparatus involved in transcendental apperception: To begin with, what exactly does Kant mean when he states that $I$ is a simple and empty representation? Secondly, can the features of the representation $I$ and the correlative 'transcendental designation' explain the indexical nature of the $I$ ? Thirdly, do the Kantian reflections on indexicality anticipate any of the semantic elements or the spirit of the direct reference theory, if nothing else?

Some sort of contiguity between the Kantian approach to $I$ think and the contemporary direct-reference theory concerning the semantic device of $I$ has been suggested in the debate. In order to address these semantic conclusions in $\$ 3$ and $\$ 4$, some metaphysical and epistemic theses, which are simply taken for granted and will not be explained in detail further, will be introduced in $₫ 2$. Even if these theses are dismissed, the semantic results could still be considered worthwhile.

Undoubtedly, as transcendental designation displays utterly unique designation features, a simple or empty representation is a representational unicum among the kinds of representations considered by Kant. In this way, it will be possible to identify the peculiarities of the representation $I$ in order to grasp the role of transcendental designation. With the designation of $I$ any application of the direct reference theory aimed at explaining the Kantian approach to indexicality will be rejected. Furthermore, as will be presented in the last paragraph, $I$ is not regarded as an indexical representation at all.

1 I will use the term "metaphysics" in its contemporary philosophical sense; that is, a metaphysics of the self that accounts for the particular types of entities known as 'selves'. While Kant asserts that "this name (metaphysics) can also be given to all of pure philosophy including this critique” (A841/B869), in the Transcendental Dialectic, he uses the term "metaphysical" to describe and label any dogmatic enterprise aimed at ascertaining the reality of God, freedom and immortality.

2 These three different questions obviously touch on the huge philosophical field of self-knowledge, which is concerned with the knowledge of one's own mental states, e.g., the knowledge of one's current experiences, thoughts, beliefs or desires. A classic problem, for instance, involves the possibility of determining what a subject is feeling or thinking at a given moment, and yet there is significant disagreement about the nature of this knowledge among scholars. The problem of the knowledge of one's mental states involves the self-conscious subjective dimension. The fact that a subject acquires knowledge of her belief that Naples is a lovely city implies that the state is registered as her own; this is related to the question of 'self-consciousness' or 'self-awareness' proper, one of the major topics in the philosophical arena. Gertler $(2011,19)$ stresses that these issues are not specifically addressed by any theory of self-knowledge; nevertheless, since a theory of self-knowledge aims to explain how the subject acknowledges her sensations, thoughts or attitudes, the problems of self-consciousness are certainly complementary to the philosophical questions related to the self-knowledge area, if nothing else but for their reference to the subject. Since expressions of self-knowledge employ terms such as "I", as in "I feel an itch", the problem of self-consciousness also concerns how the determination of the reference of $I$ and the identification of those mental states as one's own may be achieved. 


\section{Some metaphysical and epistemic theses}

In line with Capozzi (2007)'s interpretative approach on the Kantian self-knowledge and the so-called formal ownership reading, which affirms the referential function of $I$ in the peculiar and formal terms of transcendentalism, ${ }^{3}$ a few theses are advanced:

a) The identity or unity of self-consciousness does not presuppose the identity of a real subject, but a formal identity based on the representation I think.

b) Kant establishes general, metaphysical characterisations concerning the nature of the thinking subject: the thinking as spontaneity is the being itself, and

c) to some extent, such characterisations are captured by the concept of the 'transcendental subject': The thinking being represents itself as a transcendental subject $=\mathrm{x}$ through the simple representation $I .^{4}$

3 Inasmuch as it accompanies every single representation, 'I think' refers to the thinking subject, no matter its metaphysical nature. At the level of the metaphysics of the self, Kant speaks of the 'I' (das Ich), of the mind (das Gemüt), of the thinking subject (das denkende Subjekt) and of the soul (die Seele). According to this perspective, several interpretations may be singled out within the debate, among which an anti-metaphysical account is deserving of particular attention (cf. Marshall 2010). Noticeably, although some of its arguments rest on Kant's claims concerning the limits of cognition and objective significance, others are based on his rejection of rational psychology — at heart, they all aim at ruling out the possibility of a doctrine concerning the nature of the self as such. As will be seen later, even if no Erkenntnis (in Kantian technical terms) of the self is possible because no relationship between a given representation and a spatial-temporal object can be regarded as a self, Kant maintains a number of metaphysical claims regarding the nature of the thinking subject. On the other hand, the empty form of the referential apparatus in transcendental apperception has been appraised in intrinsically different ways. At first glance, Kant presents a metaphysical thesis of exclusion whereby the 'I' of the 'I think' as an intellectual representation produces no knowledge about the nature of the thinking subject or self: rather, it refers to something that, in no respect, can be said to be an object - the transcendental subject (Cassam, 1997). This approach seems to anticipate Wittgenstein's Tractatus' claims of the subject as something not belonging to, but limiting, the world (Bennett, 1974). An elusive interpretation of the 'I' in the 'I think' as having no reference has been argued more than once by the so-termed No-ownership Reading (cf. Strawson 1966, 166; Chisholm 1976, 42; Rosenberg 1986, 68; Ameriks 2000, 54). The affinity between Wittgenstein's Blue Book's argument concerning the 'I as subject' and Kant's 'I think', as alleged by a few commentators, lies precisely within this framework. Two further antithetical views on the pivotal notions of 'unity of apperception' and 'identity of self-consciousness' are central to this framework: The Substantial Ownership Reading, discussed in Henrich and Guyer's influential works, and the Formal Ownership Reading, specifically upheld by Allison (cf. Bermúdez 1994). While the Substantial Ownership Reading maintains that, in the absence of something identical or unified in different states neither identity nor unity of consciousness is possible, according to the Formal Ownership Reading the identity of self-consciousness cannot be seen as if there existed an identical or unified self. Moving from the Paralogisms chapter of the Dialectic, Allison $(2004,340)$ highlights Kant's disclosing the illusion of regarding the unity of apperception as the unity of a thing.

4 As will be see, as transcendental designation displays utterly unique designation features, a simple or empty representation is a representational unicum among the kinds of representations considered by Kant. One particular passage, generally referred to as the Stufenleiter ("stepladder") passage from the Transcendental Dialectic of $\mathrm{KrV}$, explains and classifies the varieties of representation: "The genus is representation in general (repraesentatio). Under it stands the representation with consciousness (perceptio). A perception that refers to the subject as a modification of its state is a sensation (sensatio); an 
It is in the famous passage (B 131-2) in the B-Deduction that Kant introduces $I$ think in the context of the transcendental unity of apperception. For Van Cleve $(1999,79)$, it is important to underline that it indicates both a property and a principle; namely, a principle attributing the property to certain collections of representations of being apprehended by the act of apperception:

The I think must be able to accompany all my representations; for otherwise something would be represented in me that could not be thought at all, which is as much as to say that the representation would either be impossible or else at least would be nothing for me. That representation that can be given prior to all thinking is called intuition. Thus all manifold of intuition has a necessary relation to the I think in the same subject in which this manifold is to be encountered. (B 131-2)

Soon after, Kant associates I think with spontaneity and the pure or original apperception or self-consciousness. Later, Kant calls it transcendental unity of self-consciousness to mark it as the condition for the possibility of cognition:

I also call its unity the transcendental unity of self-consciousness in order to designate the possibility of a priori cognition from it. For the manifold representations that are given in a certain intuition would not all together be my representations if they did not all together belong to a self-consciousness; i.e., as my representations (even if I am not conscious of them as such) they must yet necessarily be in accord with the condition under which alone they can stand together in a universal self-consciousness, because otherwise they would not throughout belong to me. From this original combination much may be inferred. (B 132-3)

In particular, passage B131-2 marks the incipit of the B-Deduction, condensing two crucial points that have been widely discussed by leading commentators. The first point has a general scope and concerns single representations: For a representation to represent and to be anything to the subject, the subject must be able to think of it as its own. Obviously, the point here is not that de facto representations are accompanied by the 'I think', but concerns the necessity of the possibility of representation of self-ascriptions (Allison 2004, 163). In this regard, Ameriks $(1997,58)$ refers to a 'personal quality' assigned to individual representations in order for them to display the form (E): I think that $\mathrm{x}$, I think that $\mathrm{y}$, I think that z. Similarly, Carl $(1997,153)$ refers to one's ability to make judgments from a first-person perspective, holding that "the very first sentence or ' $\$ 16^{\prime}$ gives an account of what is involved by the notion 'my representations' in terms of the notion of ' $I$ ' and the ability to make judgments from the first-person point of view".

The second point concerns the set of representations that account for a complex thought based on synthetic unity: The different representations merge into a single consciousness as a thought ascribable to a thinking subject, i.e., (T) I think that (I think that $\mathrm{x}$, I think that $\mathrm{y}, \mathrm{I}$ think that $\mathrm{z}$, etc.) (Ameriks, 1997, 58). Not only must the uses of 'I' be co-referential-the 'I' thinking $\mathrm{x}$ must be identical to the 'I' thinking $\mathrm{y}$, and so on-but the identity of the 'I think' must also concern the highest-ranking 'I think' (outside of parentheses here) upon which is based the synthesis of various representations into a single, complex thought.

objective perception is a cognition (cognitio). The latter is either an intuition or a concept (intuitus vel conceptus). The former is immediately related to the object and is singular; the latter is mediate, by means of a mark, which can be common to several things" (A320/B376). 
Taken together, for Allison $(2004,164)$, these two points determine the principle of the necessary synthetic unity of apperception, establishing a connection between the possibility of ascribing the representations to a thinking subject and the possibility of a complex thought through the 'I think': “[A]ll my representations in any given intuition must stand under the condition under which alone I can ascribe them to the identical self as my representations, and thus can grasp them together, as synthetically combined in an apperception, through the general expression I think" (B138). In passages B137 and B138 Kant holds this principle to be analytic.

The single constituents of a complex thought must be combined in a synthetic unity to allow their ascription to a single thinking subject. In particular, a single complex thought requires a unified thinking act through which the single representations $\mathrm{x}, \mathrm{y}, \mathrm{z}$ are brought into synthetic unity. Even if the I that thinks $\mathrm{x}$ is the same I that thinks $\mathrm{y}$, this does not imply an I thinking a single, complex thought; for the subject to think them together, a single act must be involved and, through this, the thinking subject brings the components of a complex thought into a synthetic unity and ascribes them to its identical self. One is the condition for the other and vice versa: The condition of possibility for the self-ascription of single representation relies on the fact that these can be brought into a synthetic unity, and the condition of possibility for such a synthetic unity is determined by the fact that the representations composing it can be ascribable to a single, thinking subject.

If a single complex thought logically involves a single thinking subject, then every single component of this complex thought must be ascribable to an identical thinking subject; in turn, the thinking subject must be aware of its identity in the synthetic unity of such a complex thought. In another famous excerpt, all this can be reformulated by stating that the analytical unity of apperception presupposes a synthetic unity:

[T] his thoroughgoing identity of the apperception of a manifold given in intuition contains a synthesis of the representations, and is possible only through the consciousness of this synthesis. For the empirical consciousness that accompanies different representations is by itself dispersed and without relation to the identity of the subject. The latter relation therefore does not yet come about by my accompanying each representation with consciousness, but rather by my adding one representation to the other and being conscious of their synthesis. Therefore it is only because I can combine a manifold of given representations in one consciousness that it is possible for me to represent the identity of the consciousness in these representations itself, i.e., the analytical unity of apperception is only possible under the presupposition of some synthetic one. (B 134)

To think is to unify the manifold conceptually; every thought expressed by a judgment must be based on the principle of transcendental apperception. For this reason, Kant holds that the $I$ is inherent in the very concept of thought (B132), determining the form of every judgment in general terms (B 406). While Kant states that the mere representation $I$ in relation to all others is the transcendental consciousness in A117, in the A-edition Paralogism, Kant addresses the relationship between all thoughts and the 'I' taken as the common subject in which they inhere to affirm that the representation $I$ features in all thoughts (A 350). The $I$ of apperception seen as a 'logically simple subject' is analytically implied in the concepts of 'thinking' or 'thoughts" (des Denkens) (B 407-8); if the $I$ is the subject of thinking (KGS 7: 134), and if it is not represented except in the form of the judgment established by the synthetic unit of apperception, then the $I$ expresses the analytical unity of apperception, which is only possible by assuming some synthetic unity. 
In the absence of epistemic mediations of identification, regarded as simple representations, the $I$ think merely designates the activity of thinking transcendentally; that is, as the nexus established in the judgment by the copula linking the representational synthesis to the synthetic unity of apperception on a conceptual basis. The possibility of thinking of oneself as subject is properly and solely given by the simple and empty representation $I$.

What is being assumed on the basis of the representation $I$ is merely an existence devoid of properties. The subject is able to know that it exists as a thinking activity, but it is not able to know what it is: Its being is inaccessible from an epistemic angle, and what is given is nothing more than thoughts that are regarded as its predicates, which do not allow us to grasp the thinking subject's nature. In the well-known passage from Paralogisms concerning a transcendental doctrine of the soul, Kant states:

At the ground of this doctrine we can place nothing but the simple and in content for itself wholly empty representation I, of which one cannot even say that it is a concept, but a mere consciousness that accompanies every concept. Through this I, or He, or It (the thing), which thinks, nothing further is represented than a transcendental subject of thoughts $=x$, which is recognized only through the thoughts that are its predicates, and about which, in abstraction, we can never have even the least concept. (A 346/B 404)

Accordingly (we are finally confronted with the semantic thesis), a few peculiarities concerning the self-referential apparatus involved in transcendental apperception appear: "[T]he subject of inherence is designated only transcendentally through the I that is appended to thoughts, without noting the least property of it, or cognizing or knowing anything at all about it" (A 355). The act of reference performed by the subject to refer to its self does not entail a mediation of knowing-it does not involve identification by means of properties ascribable to the subject itself.

With the notion of transcendental designation, Kant anticipates some of the self-reference without identification features (cf. Brook 2001). The condition of possibility for all judgments relies on the act 'I think'; at this level, the intellectual representation $I$ only designates transcendentally because no conceptual mediation is involved: It is a simple representation that has no content and merely refers to something in general, i.e., the concept of the transcendental subject- " $[\mathrm{I}]$ ts properties [of subject] are entirely abstracted from if it is designated merely through the expression ' $\mathrm{I}$ ', wholly empty of content (which I can apply to every thinking subject)" (A 355). As an empty or bare form (A443/B471), I designates but does not represent: "For in that which we call the soul, everything is in continual flux, and it has nothing abiding, except perhaps (if one insists) the I, which is simple only because this representation has no content, and hence no manifold, on account of which it seems to represent a simple object, or better put, it seems to designate one" (A 381).

As mentioned previously, the next paragraphs will examine the nature of the representation $I$ and the features of transcendental designation in depth.

\section{I think and the direct reference theory}

Some scholars have developed Kant's views on the semantic device of I think so as to appraise their analogies to contemporary claims about the direct reference of $I$ : generally, for some scholars it is legitimate to interpret the Kantian $I$ in analogy to contemporary claims 
about the direct reference of the I particularly as the act of self-reference entails no mediation of knowing, i.e., it involves no identification through properties ascribable to the subject herself.

According to the features of the direct reference theory, two theses concerning the use of the term/concept $I$ have to be highlighted: essential indexicality and lack of identification.

A) The term/concept $I$ employed in a self-conscious or I-thought is essentially indexical (cf. Kaplan [1989] and Perry's [1997] classic approaches). More specifically, $I$ is a singular term/concept governed by the token-reflexive rule, whereby every token of "I" refers to the subject that has produced or used it, either mentally or linguistically; with the information available in context, and once all evaluation circumstances are established, this rule is prima facie sufficient to determine its reference. ${ }^{5}$ Thus, moving from the contextual factors, the reference relationship between $I$ and the subject who has produced it is determined in a direct way. By virtue of the token-reflexive rule, the fact that a subject produces the relevant token "I" makes her the very referent of that token; nonetheless, the process of indexical production does not occur within the propositional or thought content. For instance, when Mario thinks the thought "I am happy", the fact that he is the subject who has produced the token $I$ determines that the $I$ refers to him; however, it is the subject, i.e., Mario, not the fact that he has produced the token, which enters the content of that thought. As a result, it can be argued that reference is direct: the singular term $I$ is directly referential.

B) The reference of the $I$ is determined without the subject observing or identifying herself as the subject who possesses a specific property: In other words, without the possibility of misidentifying or making thoughts liable to error through misidentification relative to the concept $I .{ }^{6}$ It is a fact that a subject produces an occurrence of "I" that guarantees that this "I" will refer to that subject, not to the subject's observation and identification of herself. Indexical information about oneself based on the use of $I$ cannot be reduced to non-indexical information; for this reason, in-

5 This approach to indexicality has been acknowledged by major scholars, cf. Shoemaker $(1968,91)$, Peacocke (1983, 133-9), Rovane (1987, 147), Campbell (1994, 73), Kaplan (1989, 493). Nonetheless, their positions are not entirely uniform-cf. Castañeda (1983; 1989), Kapitan (2001; 2008), and de Gaynesford (2006) for an analysis of the debate.

6 Due to the absence of identification components, some singular judgments involving self-ascriptions of mental and physical properties are immune to error through misidentification relative to the first-person pronoun. The subject formulating such judgments in given epistemic contexts cannot be mistaken as to whether it is she who is attributing a particular property to his own self. The issue is introduced by Wittgenstein (1958: 66f) in his philosophico-linguistic analysis of the grammatical rule of the term I: here he distinguishes two uses, the use as object ("I have grown six inches"), and the use as subject ("I have a toothache"), where no subject identification is taken into account. On this issue, see the classic discussions by Strawson (1966) (criterionless self-ascription); Shoemaker (1968) (self-reference without identification); "Evans (1982)" (identification-free). In Forgione (2015a), several Kantian interpretative readings in the debate have been taken into account and discussed in order to place the I think feature in its appropriate context with respect to the question of self-identification, and, above all, to point out the difference with Wittgenstein's approach and the contemporary debate. 
dexicality is essential. In other words, token-reflexive expressions such as the term/ concept "I" are essential indexicals, as they cannot be eliminated or replaced by names, descriptions or demonstratives without losing the content expressed by the sentences/thoughts that contain them: To refer to (to think) of oneself qua oneself, the subject has to use the essential indexical $I$. 'Essentiality' lies in the fact that, although the use of $I$ is not based on any cognitive mediation, it is indispensable in order to form I-thoughts; this entails that an identifying description is a neither a necessary nor sufficient condition for the subject to refer to herself.

As mentioned in the previous paragraph, a few peculiarities of the self-referential apparatus involved in transcendental apperception due to the fact that the subject is designated only transcendentally through the $I$ attached to thoughts emerged, without noting or cognising its least property. The act of reference performed by the subject to refer to itself entails no mediation of knowing, as it involves no identification through properties ascribable to the subject herself. The crucial point is to ascertain whether there is any clue about the idea of the direct reference of $I$ in the Kantian approach. It is noteworthy that, according to some contemporary perspectives, the phenomenon of the lack of identification in self-reference entails that indexical reference to the self is both essential and grounded in direct reference because the act of self-reference is independent of non-indexical identification.

As mentioned previously, Kant introduces the notion of 'transcendental designation' by pointing out that $I$ is a simple representation: no manifold is given (B135). In A355 of the recently mentioned first-edition attack on the second Paralogism, Kant crucially claims that, by attaching $I$ to its thoughts, the subject is only designated transcendentally, without noting any quality in it: The entirely empty of content $I$ may be applied to every thinking subject without knowing or identifying anything about it, either directly or by inference. The act of reference that produces the awareness of oneself as a subject is non-ascriptive-it displays no properties of oneself. The non-ascriptive feature of the self-conscious subject's self-reference is reasserted in B155 in the second edition, where Kant contends that, from a representational perspective, even if the subject is the same, the 'I that thinks' is distinct from 'the I that intuits'. The subject is given to itself beyond what is given in intuition.

In B422, the subject of the categories is considered to be unable to acquire a concept of itself as an object via the categories: In order to think of them, pure self-consciousness itself-namely, what must be explained-must be assumed. Moving on from this, Brook (2001) suggests that, in some respects, Kant is aware of the fact that the use of indexicals such as 'I' is essential for certain purposes because awareness of oneself as a 'subject of the categories' relies on an act of ascription-free transcendental designation: It follows that, if identification-free self-reference appears to imply the essentiality of those first-person indexicals involved in judgements, the pure self-consciousness resulting from it captures the subject's ability to be self-conscious as a subject (Brook 2001, 1994).

Howell (2000) is a scholar who has possibly explored this specific issue in the closest detail in recent years. Several authors-from Henrich and Frank to Ameriks and Sturmahave dealt expressly with the issue of the lack of identification, as has been touched upon previously; however, Howell $(2000,145-6)$ contends that they have failed to recognise that much of Kant's account of 'I think' is related to his semantic account of the $I$ as addressed by contemporary direct reference theorists, whose perspective provides the best approach 
to the Kantian approach to self-awareness. Howell has discussed the issue at greater length than has Brook, maintaining that, at the level of representational thought, the Kantian approach to 'I think' is, in some respects, similar to the contemporary direct-reference views on the linguistic reference of $I$ : "Given its own intellectual virtues, the direct-reference framework thus offers the best current way of coming to grips with the distinctive (and I think correct) points in Kant's account".

According to the theory of direct reference, the major point highlighted by Howell concerns the way in which $I$ refers to the subject: The subject's self-reference via $I$ establishes a directly referential relationship between the subject and herself by importing the entity she is - the subject herself-into the thought's content, without involving any of the subject's properties. In other words, the relationship of designation between $I$ and the subject is direct, and the propertyless nature of this relationship introduces the thing designated-the self-into the content of the 'I-thought'. In the same manner, the scholar $(2000$, 134) highlights that Kant introduces a special representation of the self, the $I$ in $I$ think, which is supposed to be simple precisely because the designation that is called "transcendental" ensures that the representation $I$ "gets us, by itself, into the designation relation with a specific being, our self, although it does not thereby enable us to distinguish that being from other beings".

In this scenario, and in keeping with the mental token-reflexive rule (whereby every token of "I" refers to the subject who has produced it), the $I$ in $I$ think is regarded as a mental indexical that represents the subject in a direct fashion; what is introduced into the content of the thoughts is none of the subject's properties but its very self. Beyond that sheer entity, i.e., "the being itself" (B429), nothing else can be introduced or known about the subject given to itself. It follows that, in producing the act of thought, the subject produces the representation $I$, and since it does so by virtue of the token-reflexive rule, ${ }^{7}$ the subject can refer to itself in a directly referential manner, i.e., by establishing a propertyless designation relationship between the $I$ in $I$ think and the subject-producer.

This account presents two specific consequences. Firstly, Howell does not expressly agree with the conceptualist view presented in a particularly unequivocal way in the Paralogisms, whereby the acts of the 'I-thought' cannot grasp the subject as an individuated object: in these passages, I think is regarded as the completely undetermined concept of a thinking being in general. Expanding on this concept, Howell reinterprets $I$ think as a thought that determines the unique being that thinks- whatever it turns out to be-in a de dicto fashion; given that, in this de dicto manner, the concept of a subject of thoughts does not connect the subject to itself in any way, this conceptualist construal is ultimately rejected by Howell.

Howell does not support a de re interpretation either. Certainly, when a direct reference theory is used to explain the designation of $I$ think, a de re reading should be examined in depth with regard to the issue of the relationship of (self-)acquaintance. For example, in his paper The First Person, Kripke $(2011,305)$ states that "it is a rule of the common language that each of us fixes the reference of 'I' by the description 'the subject'". As Peacocke $(2014,84)$ points out, it is clear that, for Kripke, the grasp of the first-person concept does

Similarly, Longuenesse $(2017,31)$ and Peacocke $(2014,170)$ draw on the use of the mental token-reflexive rule in order to specify how the reference of "I" in 'I think' is determined. 
not rely on a thinker's use of some definite description (the thinker); what matters is the thinker's position in a relationship of acquaintance to herself produced by the fact that she is the subject of certain mental events and states: "Each one of us can fix the reference of the word 'I' by means of acquaintance with oneself, self-acquaintance" (Kripke 2011, 302); in this way, "self-acquaintance is more fundamental than anything purely linguistic, and is the basis of our use of first person locutions" $(2011,320)$. The point is to explain what kind of relationship the acquaintance is in order to make the de se content available in the thought. Lewis (1979) considers identity to be a relationship of acquaintance par excellence; thus, de se beliefs are assessed as de re beliefs based on a causal dependence. Peacocke offers quite a different perspective concerning the first person concept:

\footnotetext{
It seems to be the case that the de se way of thinking is always distinct from any way of thinking grounded in acquaintance relations that are a matter of causal dependence. As is famously the case, the thought $I$ am identical with that $F$, where that $F$ is either a perceptual demonstrative, or a memory demonstrative, or a recognitional notion or concept, seems always to be potentially informative, provided that the demonstrative or recognitional notion or concept does not embed the first person itself. The relations in virtue of which the first person has the reference it does are distinct from the causal-dependence relations that ground these other demonstrative and recognitional notions. (Peacocke 2014, 102)
}

Even though Howell does not develop the issue in this way, and a comprehensive evaluation of Peacocke's perspective is not possible in this context, it is worth pointing out the possibility of considering a constitutive variety of self-acquaintance made available by consciousness, which is different from the de re modes of acquaintance explicated in terms of causal dependence on the model of perception, establishing a genuinely indexical way of thinking of a subject.

It seems that this is the Howell's view, as he doesn't sustain a de re account explicated in terms of causal dependence on the model of perception: According to this, and based on a relationship of acquaintance, $I$ is a mental, indexical representation that represents its referent through a relationship between the occurrence of a thought and the subject. However, the representation $I$ is not an intuition, i.e. the kind of representation that presents a semantic device which, under certain perceptual conditions, establishes an indexical relationship between the representation and the object designated, as will be mentioned in the following paragraphs. It is Howell himself $(2000,138)$ who stresses this point, maintaining that the 'I think act' cannot possibly give the subject "the de re thought-awareness of a self that the producer grasps in some mysterious fashion as a definite but wholly propertyless entity, a bare particular."

This interpretation should be extended to counterbalance the different and, at first glance, incompatible views concerning this issue. In any event, it seems impossible to follow a Kantian reading of $I$ think according to the direct reference theory for two reasons one general and the other particular. Firstly, Kant firmly rejects any possible relationship between the $I$ and the self in a direct way, enabling the subject to get into the content of its thought. Secondly, and with regard to the general considerations on indexicality I have tried to expound elsewhere (cf. Forgione 2015b), not only is the representation $I$ not an intuition (the main representation connected to an indexical component), but the phenomenon of indexicality addressed by Kant cannot be investigated in terms of the direct reference the- 
ory because it is essentially bound to a conceptual dimension; this is also apparent when the Kantian approach to the semantics of natural kind terms are discussed (cf. Forgione 2016).

In the next paragraph, it will be possible to understand the peculiarities of the simple and empty representation $I$ and the role played by transcendental designation in order to verify whether these are compatible and consistent with the frame lying in the three (metaphysical, epistemic and semantic) theses developed previously. Even if these theses are dismissed, the semantic considerations and the dismissal of the direct reference theory could still be considered worthwhile.

\section{The simple representation ' $I$ ' and the role of transcendental designation}

As mentioned, 'thinking' is the synthetic unity of apperception determining I think (qua Representation) as an analytic unity of apperception: I think is the representation through which spontaneity or thinking is given to oneself. Regarded as a simple representation (cf. B135, B138, A345/B404, A355 and many others), the representation I think simply designates the activity of thinking transcendentally. The concept of the transcendental subject $(=\mathrm{x})$ has also been taken into account and regarded as the indeterminate thought of a thinking being with an existence in itself; on the other hand, the $I$ in $I$ think has been seen as the representation through which this thought is expressed.

At the same time, the logical feature of the concept $I$ introduces the well-known distinction between logical and real features of the self, or between features of the self as a real entity and features of the self as a logical entity. Following Rosefeldt $(2003,147)$ "a logical subject is everything of which we can predicate something, i.e. everything the concept of which we can use as the subject-concept in a judgement"; instead, a real subject is a substance, something in which properties inhere. This distinction points out the fact that not everything of which we can predicate something in a judgement is a thing in which properties inhere.

At the very heart of the Transcendental Deduction Kant states that the $I$ is a representation of the identical self; however, this identity presents nothing but a logical nature, as "through the I, as a simple representation, nothing manifold is given" (B135). Apart from the simple or empty representation $I$, the subject has no acquaintance with itself since this representation $I$ cannot be identified with a spatio-temporal object. It is precisely for this reason that Kant states that the thinking subject can only know that its self is the 'permanent logical subject of thinking', and not that it is a 'real subject of inherence' (A 350).

In other words, the thinking being represents itself as a transcendental subject $(=\mathrm{x})$ through the completely empty representation $I$. Hence, the concept of the transcendental subject amounts to the representation $I$, or the logical $I$-while $I$ is the simple and entirely empty representation, the transcendental subject $(=\mathrm{x})$ is what is represented. The $I$ appended to thoughts is simple as it doesn't represent any property, signifying only 'a something in general' or 'a transcendental subject': "Nothing can be represented as more simple than that which is represented through the concept of a mere Something" (A355). With reference to the Copernican turn, in the transcendental approach a first-order talk about objects is replaced by a second-order discussion of the concept of an object and the conditions for the representation of an object. However, with regard to 'thinking', Kant often moves from the first-order discussion of its nature-for instance, when he maintains 
that the thinking is the being itself-to the second-order talk. By virtue of the concept of 'a transcendental subject' (or of 'a something in general') and the representation $I$, here he employs the second-order discussion, through which the thinking being represents its relationship with itself as a subject of inherence and, in turn, the latter is designated transcendentally through the simple representation $I$ :

But it is obvious that the subject of inherence is designated only transcendentally through the I that is appended to thoughts, without noting the least property of it, or cognizing or knowing anything at all about it. It signifies only a Something in general (a transcendental subject), the representation of which must of course be simple, just because one determines nothing at all about it; for certainly nothing can be represented as more simple than that which is represented through the concept of a mere Something. But the simplicity of the representation of a subject is not therefore a cognition of the simplicity of the subject itself, since its properties are entirely abstracted from if it is designated merely through the expression "I", wholly empty of content (which I can apply to every thinking subject). (A 355)

\section{Kant restates this point in his Metaphysical Foundations of Natural Science:}

The $I$, the general correlate of apperception, and itself merely a thought, designates, as a mere prefix, a thing of undetermined meaning-namely, the subject of all predicates-without any condition at all that would distinguish this representation of the subject from that of a something in general: a substance, therefore, of which, by this term, one has no concept of what it may be. (MAN 4: 542-3, 82)

Assuming the relationship between the synthetic unity of apperception and I think (qua Representation) as an analytic unity of apperception, the $I$ stands for the thinking being as follows: Due to this representation, the thinking being can think of itself as a thinking subject and refer to itself through the transcendental designation, i.e., the self-referential apparatus involved in transcendental apperception. The $I$ is a simple representation, which does not convey any content and simply signifies 'a something in general' or 'a transcendental subject': As the properties of a thinking being are entirely abstracted, this is designated through the completely empty of content expression "I". In this scenario, if the $I$ simply signifies 'a something in general', namely 'a transcendental subject', then the $I$ is a representational unicum, as it is neither intuition nor concept:

For in that which we call the soul, everything is in continual flux, and it has nothing abiding, except perhaps (if one insists) the I, which is simple only because this representation has no content, and hence no manifold, on account of which it seems to represent a simple object, or better put, it seems to designate one. This I would have to be an intuition, which, since it would be presupposed in all thinking in general (prior to all experience), would, as an intuition, supply a priori synthetic propositions if it were to be possible to bring about a pure rational cognition of the nature of a thinking being in general. Yet this $I$ is no more an intuition than it is a concept of any object; rather, it is the mere form of consciousness, which accompanies both sorts of representations and which can elevate them to cognitions only insofar as something else is given in intuition, which provides the material for the representation of an object. (A381-2)

It is interesting that Kant ponders the possibility of regarding $I$ as an intuition, with the ultimate aim of demonstrating quite the reverse. Were it possible to construe a pure, rational 
cognition, $I$ should be an intuition - and a pure one, too-coming into play to form a priori, synthetic propositions about the nature of the thinking being; in spite of that, this is not possible according to the Paralogisms section. It is worth noting that the $I$ could also be regarded as an intuition at first glance, as it displays some of the features summed up as the intuition conditions: ${ }^{8}$ a singular representation denoting an individual object (the singularity condition), as opposed to the concept which relates to different objects falling under it and grounded in an immediate relationship with its denotation (the immediacy condition), as opposed to concepts referring to the object through the mediation of the conceptual features, or marks, composing the concept's very intention. Prima facie, it might seem possible, for instance, to account for the features of simplicity or emptiness of $\Gamma$ s representational form by the immediacy condition. If one also recalls the Kantian consideration that the expression "I", which is completely devoid of content, can be applied to every thinking subject (A 355), then Kant does seem to anticipate a contemporary proto-approach to indexicality, even based on the direct reference theory, as argued by Howell (2000). Accordingly, and based on indexical features, $I$ is a singular term/concept with a single individual as its reference, and is governed by the token-reflexive rule, whereby every token of "I" refers to the subject who has produced or used it (cf. supra, $₫ 3$ ). To rule out any Kantian interpretation based on the direct reference theory, some points need be discussed.

Firstly, the $I$ is an intellectual representation, not an intuition corresponding to whichever indexical condition is associated with sensibility: In no respect can the thinking being be regarded as a spatio-temporal object, as it is nothing more than that through which an object can be determined and known. As a result, the properties of a subject are entirely and necessarily abstracted, precisely because they cannot be determined at all:

[T] he consciousness in itself is not even a representation distinguishing a particular object, but rather a form of representation in general, insofar as it is to be called a cognition; for of it alone can I say that through it I think anything. (B404/A346)

The 'I' exists in all thoughts; but not even the least intuition is involved in this representation, which would distinguish it from other objects of intuition (A350):

Thinking, taken in itself, is merely the logical function and hence the sheer spontaneity of combining the manifold of a merely possible intuition; and in no way does it present the subject of consciousness as appearance, merely because it takes no account at all of the kind of intuition, whether it is sensible or intellectual. (B428-9)

8 Ever since the mathematical/philosophical debate aroused by Hintikka and Parsons' essays (cf. Posy 1992, which contains these as well as other interventions), there have been identified a number of conditions a representation must meet to amount to an intuition. I will only mention two of them (cf. A19/B33), bearing in mind that they are objects of a heated dispute within the theoretical debate: (a) the singularity condition, a criterion based on the type of denotation involved, whereby intuition is a singular representation denoting an individual object as opposed to concepts denoting different objects that fall under it, owing to the presence of the very property the concepts represent; (b) the immediacy condition, which concerns the type of relationship-obviously immediate-a particular representation shares with its denotation as opposed to concepts referring to an object in a mediated way through those conceptual features (or marks) that compose the very concept's intension. 
Moreover, if $I$ cannot be said to be an intuitional representation due to the absence of any type of relationship to the sensible spatio-temporal forms, it is not conceptual either. The $I$ does not represent any thinking subject conceptually, because it employs neither content mediation nor a prior instance of identification articulated in conceptual marks: An empty or bare form (A443/B471) is quite the reverse of the definition of the concept as a common representation, which is not free from extension and is subject to further determination at all times.

In A381, Kant remarks that, at first glance, the $I$ seems to designate rather than to represent: "[the I] is simple only because this representation has no content, and hence no manifold, on account of which it seems to represent a simple object, or better put, it seems to designate one." It is better to state that $I$ seems to designate rather than to represent, as it seems to refer to a simple object (the thinking being) that has no properties to be articulated into conceptual or representational marks in turn. However, by recalling the formal reading used in these pages, and by highlighting passage A355, it is not possible to insist that there is any material or immaterial substance to be referred to by $I: I$ is a simple representation not because it designates a simple object, but because it has no content at all; in other words, no manifold.

More specifically, the $I$ appended to thoughts designates the 'subject of inherence' transcendentally: The $I$ stands for the 'subject of inherence' or the 'subject of all predicates', which is not the real thinking subject-the thinking being-but concerns a mere logical role which is filled by the concept of 'a transcendental subject' or 'a something in general' instead. As said previously, there is a difference between the logical and real features of the subject, and thanks to this difference it is possible to state without fear of contradiction that the $I$ is both not a (general) conceptual representation and a simple representation which stands for the concept of 'a transcendental subject' or 'a something in general". If the former is simple-nothing is simpler than the concept of 'a mere something' (A355) then the $I$ also has to be a 'simple' or 'empty' representation.

The point is also stated in A350, in which Kant critically points out that the first syllogism of transcendental psychology "imposes on us an only allegedly new insight", as it mistakes "the constant logical subject of thinking" for "the cognition of a real subject of inherence with which we do not and cannot have the least acquaintance." In Kant's view, "consciousness is the one single thing that makes all representations into thoughts, and in which, therefore, as in the transcendental subject, our perceptions must be encountered". Later, Kant claims that, "apart from this logical significance of the $I$, we have no acquaintance with the subject in itself that grounds this I as a substratum, just as it grounds all thoughts" (Italics added). For this reason, Kant states that the thinking subject can only know that its self is the 'permanent logical subject of thinking', and not that it is a 'real subject of inherence’ (A 350).

Accordingly, both a general conceptualist/descriptivist strategy and strict indexical approach based on the direct reference theory have to be dismissed.

A) As has been mentioned in $\S 1$, by availing himself of the mental token-reflexive rule (R), Howell regards the $I$ in $I$ think as a mental indexical that represents the subject in a direct fashion: No properties of the subject are introduced into the contents of the thoughts other than the subject's self. In particular, Howell's analysis displays several specific features: 1) a rejection of the conceptualist view, whereby 
I think is regarded as the completely undetermined concept of a thinking being in general, 2) the use of the direct reference theory, according to which the subject's self-reference via "I" establishes a directly referential relation to herself, importing the entity she is into the thought's content, and 3) the ensuing use of the mental token-reflexive rule $(\mathrm{R})$ in order to specify how the reference of "I" is determined. The critical point is that it has just been seen that a conceptualist view of $I$ think is expressed in a clear-cut way, especially in the passages from the Paralogisms: I think must be regarded as the concept of a thinking being in general. Thus, it doesn't seem that the relationship between $I$ in $I$ think and the thinking being is a relation of designation which introduces the entity designated-the subject-into the content of the 'I-thought' in a directly referential way.

B) This does not entail that I think should be regarded as a thought that, in a de dicto fashion, determines the unique thinking being-whichever it turns out to be-that corresponds to the concept: The $I$ does not designate the subject-entity through the concept of 'a transcendental subject' or 'a something in general', as this would entail that the relation of designation is not of the propertyless type that Kant attributes to the $I$. As said previously, according to the difference between logical and real features, the representation $I$ only designates a logical subject, i.e. the subject of all predicates, which cannot be distinguished from the concept of 'a something in general' and, above all, has to be precisely considered only as a mere logical role. Since this concept doesn't express a real feature of thinking subject, the $I$ cannot designate it in a de dicto fashion.

In this way, even if the $I$ stands for an existence devoid of properties, it does have a logical role that is fulfilled by the concept of 'a transcendental subject': As the representational correlate of transcendental apperception, the $I$ designates the thinking being in self-consciousness because it is analytically contained in the synthetic unity of apperception as the representation of (the concept of) 'a something in general' or 'a transcendental subject'.

In a nutshell, the $I$ designates the thinking being not because it is the representation of 'a transcendental subject' that designates the thinking being in a de dicto fashion; neither does the $I$ designate the thinking being because it is an indexical representation that designates its referent through a self-acquaintance relationship or a relationship linking the occurrence of a thought with the thinking being in a de re fashion: Kant firmly states that the thinking being is not an object of self-acquaintance ("apart from this logical significance of the I, we have no acquaintance with the subject in itself" A350) or perceptual relationship (B428-9). Instead, the $I$ designates the thinking being inasmuch as this is analytically contained as a representation in the synthetic unity of apperception: For this reason, its origin is not indexical at all. It is necessary to recall the theses posited previously in order to develop this semantic conclusion concerning the transcendental designation of $I$.

Since the transcendental apperception is an intellectual awareness of self-existence, the thinking being is an existence devoid of properties represented to such an extent that Kant leaves the pronoun indeterminate ('I', 'he', 'it'): “[I]n the synthetic original unity of apperception, I am conscious of myself not as I appear to myself, nor as I am in myself, but only that I am. This representation is a thinking" (B157); "Through this I, or He, or It (the thing), which thinks, nothing further is represented than a transcendental subject of 
thoughts $=\mathrm{x}$ " (A346/B404); "in the consciousness of myself in mere thinking I am the being itself, about which, however, nothing yet is thereby given to me for thinking” (B429).

On one hand, it seems possible to derive an approach on the nature of the determining thinking being: As has been mentioned above, the principle of the unity of apperception expresses the statement "the synthetic unity of consciousness is an objective condition of all cognition”, i.e., an analytical principle asserting that all representations must stand under such a principle in order to ascribe them to an identical self as its representations; only in this way can they be grasped as a synthetically combined whole in this act of apperception of conjunction. At the same time, the subjective component comes into play to affirm a first-person perspective: A single complex thought logically involves a single subjective dimension; every single component of such a complex thought is ascribable to an identical thinking subject - thus, the thinking being becomes aware of its identity as a thinking subject in the synthetic unity of such a complex thought. Kant elaborates on this point in the famous passage B 134 in which he states that the analytical unity of apperception presupposes a synthetic unity.

On the other hand, when the first-order discussion about the 'thinking being' or the synthetic unity of consciousness is replaced by the second-order discussion, the representation $I$ is introduced, and the determining subject is therefore enabled to represent its relationship with itself from its first-person perspective. As the representational correlate of apperception, the $I$ is the representation of a logical subject, and yet it is to be understood as the representation of 'a something in general'-just as self-consciousness is an intellectual awareness of self-existence-that is, something unidentifiable from an epistemic angle. What is represented is a transcendental subject of thoughts $(=\mathrm{x})$ that can only be recognised through the thoughts that are its predicates. As mentioned previously, the fact that the transcendental subject of thoughts $=\mathrm{x}$ is only recognised through the thoughts that are its predicates amounts to saying that the analytical unity of apperception is only possible under the presupposition of some synthetic unity (B133-134). The former is a second-order approach that introduces the first-person perspective through $I$ think qua representation; the latter, on the other hand, consists of a first-order approach that takes the 'thinking' as a synthetic unity of apperception in a completely impersonal way into account.

\section{Conclusion}

It is not possible to explain transcendental designation on the basis of the direct reference theory. If to think is to unify the manifold conceptually, and hence every single thought expressed by a judgment is grounded in the principle of transcendental apperception, then the $I$ simply expresses the analytical unity of apperception, which is only possible under the presupposition of a synthetic unity. In other words, and from a second-order perspective, the $I$ is the representation that is inherent in the very concept of thought (B132); in the A-edition Paralogism, Kant tackles the relationship of all thoughts and the 'I' taken as the common subject to which they inhere to affirm that the representation 'I' features in all thoughts (A 350). Kant sees the $I$ as the nexus established by the copula in the judgment by the representational synthesis of the unity of apperception. In other and more concise words, the $I$ is solely given as the analytical form of thought. In a way, not only in the inner 
sense but also at the heart of transcendental apperception proper, Kant is more Humean than Hume himself.

If the $I$ of apperception is not originated by the mental token-reflexive rule but is seen, instead, as the representation of a logically simple subject analytically contained in the concepts of 'thinking' or 'thoughts" (des Denkens) (B 407-8), then it must determine (i.e., it is inherent in) the form of every judgment in general terms (B 406): For this reason, Kant can state, in a quite indexical fashion, that the wholly empty of content $I$ can be applied to every thinking subject (A 355). This implies that the subject's self-reference via $I$ does not import any entity into the thought's content: The $I$ is the representation of the subject of thinking (KGS 7: 134), but the thinking being is represented in nothing other than the form of the judgment. Thus, the possibility of thinking of oneself as a subject is not given by importing the entity of which the subject consists into the thought's content, but properly and solely by the form of the thought that, analytically, contains the simple and empty $I$.

In brief, it is not an entity in the thought's content, which could justify the indexical nature of $I$, or the thought of the 'thinking subject', which could determine the reference of the subject through the mediation of properties in a de dicto fashion-as there is no property to associate with the 'thinking being', except for the fact (but, again, not the property!) that it exists-but only the form of 'spontaneity' or 'thinking' that contains the representation $I$.

Kant's view and naming of the designation of apperception of $I$ "transcendental" is further evidence of the fact that the origin of $I$ as the representational correlate of the synthetic unity of transcendental apperception is not indexical. It is known that Kant calls all cognition that is concerned not with objects but with their a priori concepts "transcendental" (hence, Transcendental Philosophy is the general system of such concepts; A12); furthermore, Kant specifies that not all a priori cognition must be called "transcendental", "but only that by means of which we cognize that and how certain representations (intuitions or concepts) are applied entirely a priori, or are possible (i.e. the possibility of cognition or its use a priori)" (A56/B 81). Regarded as a simple representation, I think designates transcendentally the activity of thinking given by the synthetic unity of apperception, namely as the nexus established in the judgment by the copula serving as the link between the representational synthesis and the synthetic unity of apperception on a conceptual basis. It follows that the transcendental designation is concerned with the conditions of possibility for and how the representation I think is used a priori-given that the designation of $I$ is transcendentally inherent in the 'thinking' - and not by picking out some entity a posteriori. In conclusion, I think consists of the representation that means the concept of the transcendental subject and presents a designative function referring to something that really exists as (an act of) Thinking (Being) for no other reason than that 'thinking' as spontaneity is the synthetic unity of apperception that contains the representation $I$ think as an analytical unity of apperception.

\section{REFERENCES}

Allison, Henry. 2004. Kant's transcendental idealism. An interpretation and defense. Revised and Enlarged Edition. New Haven and London: Yale University Press.

Ameriks, Karl. 2000. Kant's theory of mind (2d ed.). Oxford: Oxford University Press. 
Becker, Wolfgang. 1984. Selbstbewusstsein und Erfahrung: zu Kants transzendentaler Deduktion und ihrer argumentativen Rekonstruktion. Freiburg: K. Alber.

Bennett, Jonathan. 1974. Kant's dialectic. New York: Cambridge University Press.

Bermúdez, José Luis. 1994. The unity of apperception in the critique of pure reason. European Journal of Philosophy 2: 213-240.

Brook, Andrew. 1994. Kant and the mind. Cambridge: Cambridge University Press.

Brook, Andrew. 2001. Kant, self-awareness and self-reference. In A. Brook and R.C. DeVidi, eds., Self-reference and self-awareness, 9-30. Philadelphia: John Benjamins.

Campbell, John. 1994. Past, space and self. Cambridge MA: MIT Press.

Capozzi, Mirella. 2007. L'io e la conoscenza di sé in Kant. In E. Canone, ed., Per una storia del concetto di mente, 267-326. Firenze: Olschki.

Castañeda, Hector-Neri. 1983. Reply to John Perry: Meaning, Belief, and Reference. In J. Tomberlin, ed., Agent, language, and the structure of the world, 313-328. Indianapolis: Hackett.

Castañeda, Hector-Neri. 1989. Thinking, language, and experience. Minneapolis: University of Minnesota Press.

Cassam, Quassim. 1997. Self and world. Oxford: Oxford University Press.

Chisholm, Roderick. 1976. Person and object: A metaphysical study. Chicago and La Salle: Open Court.

de Gaynesford, Maximilian. 2006. I: The meaning of the first person term. Oxford: Oxford University Press.

Evans, Gareth. 1982. The varieties of reference. Oxford: Oxford University Press.

Forgione, Luca. 2015a. Kant and the problem of self-identification. Organon F. 22/2: 178-198.

Forgione, Luca 2015b. Kant on de re: some aspects of the Kantian non-conceptualism debate. Kant Studies on line, 2: 32-64.

Forgione, Luca 2016. Kant and natural kind terms. Theoria: An International Journal for Theory, History and Foundations of Science 31/1: 55-72.

Gertler, Brie. 2011. Self-knowledge. London: Routledge.

Guyer, Paul. 1987. Kant and the claims of knowledge. Cambridge: Cambridge University Press.

Hanna, Robert. 2008. Kantian non-conceptualism. Philosophical Studies 137/1: 41-64.

Henrich, Dieter. 1976. Identität und Objektivität. Eine Untersuchung über Kants transzendentale Deduktion. Heidelberg: Winter.

Henrich, Dieter. 1989. The Identity of the subject in the transcendental deduction. In E. Schaper and W. Vossenkuhl, eds. Reading Kant, 250-280. Oxford: Basil Blackwell.

Howell, Robert. 2000. Kant, the I think, and self-awareness. In P. Cicovacki, ed., Kant's legacy: Essays in honor of Lewis White Beck, 117-152. Rochester: University of Rochester Press.

Kant, Immanuel. 1900-. Gesammelte Schriften (KGS) Hrsg.: voll. 1-22, Preussische Akademie der Wissenschaften; from vol. 23, Deutsche Akademie der Wissenschaften zu Berlin; from vol. 24, Akademie der Wissenschaften zu Göttingen. Berlin: de Gruyter.

Kant, Immanuel. 1781-87. Critique of pure reason (KrV). Cambridge: Cambridge University Press, 1997.

Kant, Immanuel. 1786. Metaphysical foundations of natural science $(M A N)$. Cambridge: Cambridge University Press, 2004.

Kapitan, Tomis. 2001. Indexical identification: A perspectival account. Philosophical Psychology 14/3: 293312.

Kapitan, Tomis. 2008. Perry, Castañeda, and 'I'. In The XVIIIth edition of the Inter-University Workshop on Philosophy and Cognitive Science. Available at <http://fs-morente.filos.ucm.es/actividades/2008/conference/papers/Kapitan.pdf>.

Kaplan, David. 1989. Demonstratives and afterthoughts. In J. Almog, J. Perry, H. Wettstein H., eds., Themes from Kaplan, 481-614. Oxford: Oxford University Press.

Kitcher, Patricia. 1990. Kant's Transcendental Psychology. New York: Oxford University Press.

Kitcher, Patricia. 1998. Kant's cognitive self. In P. Kitcher, ed., Critique of pure reason: Critical essays. 59-84. Lanham, Maryland: Rowman and Littlefield.

Kripke, Saul. 2011. The first person. In S. Kripke, ed., Philosophical troubles, vol. 1. 292-321. New York: Oxford University Press. 
Lewis, David. 1979. Attitudes de dicto and de se. In D. Lewis., Philosophical Papers, 133-159. Oxford: Oxford University Press.

Longuenesse, Beatrice. 2017. I, me, mine. Back to Kant, and back again. Oxford: Oxford University Press.

Marshall, Colin. 2010. Kant's metaphysics of the self. Philosophers' Imprint 10/8:1-21.

McDowell, John. 1994. Mind and world. Cambridge: Cambridge University Press.

Peacocke, Christopher. 1983. Castañeda on he and I. In J. Tomberlin, ed., Agent, language, and the structure of the world, 15-42. Indianapolis: Hackett Publishing.

Peacocke, Christopher. 2014. The Mirror of the world. Oxford: Oxford University Press.

Perry John.1997. Indexicals and demonstratives. In B. Hale and C. Wright, eds., A Companion to the philosophy of language, 586-612. Oxford: Blackwell.

Posy, Carl.1992. Kant's philosophy of mathematics: modern essays. Dordrecht: Kluwer Academic Publishers.

Powell, C. Thomas. 1990. Kant's theory of self-consciousness. Oxford: Oxford University Press.

Rosefeldt, Tobias. 2003. Kant's self: Real entity and logical identity. In H.J. Glock, ed., Strawson and Kant, 141-54. Oxford: Oxford University Press.

Rosenberg, Jay. 1986. 'I thinks': Some reflections on Kant's paralogisms. Midwest Studies in Philosophy 10 (1): 503-530.

Rovane Carol. 1987. The epistemology of first-person reference. Journal of Philosophy 84: 147-67.

Schulting, Denis. 2011. Limitation and Idealism: Kant's 'Long' Argument from the Categories. In D. Schulting and J. Verburgt, eds., Kant's idealism. New interpretations of a controversial doctrine, 159-191. Dordrecht/Heidelberg: Springer Science.

Shoemaker, Sydney. 1968. Self-reference and self-awareness. Journal of Philosophy 65: 555-567.

Strawson, Peter F. 1966. The bounds of sense. An essay on Kant's critique of pure reason. London: Methuen.

Sturma, Dieter. 1985. Kant über Selbstbewusstsein. New York: Georg Olms Verlag.

Wittgenstein, Ludwig. 1958. The blue and the brown books. Oxford: Blackwell.

LUCA FORGIONE holds the position of Associate Professor of Philosophy and Theory of Languages at the Department of Humanities of the University of Basilicata (Italy). He received his doctorate in philosophy of language from the University of Naples "L'Orientale". His research focuses primarily on the philosophy of language, philosophy of mind, self-knowledge, with particular reference to Kant. His publications include various articles in international journals and two works presented at the 11 th and the 12 th International Kant Congress organized by the International Kant Society. His last book is entitled Kant and the problem of self-knowledge.

AddRess: Department of Humanities, University of Basilicata, via Nazario Sauro 85 - 85100 Potenza (Italia). Email: luca.forgione@unibas.it 